\title{
WHOLE PERSON CARE
}

VOLUME $5 \bullet$ NUMBER $1 \bullet 2018 \bullet 46-47$

\section{MINDFUL CONGRUENCE, FOUR NOBLE TRUTHS AND HEALING RELATIONSHIPS}

\section{Patricia Lynn Dobkin}

Department of Medicine and Programs in Whole Person Care, McGill University, Montreal, Quebec, Canada patricia.dobkin@mcgill.ca

A

midst the commotion of constant changes in health care systems, budget cuts, burnout and compassion fatigue there are resilient clinicians who relieve suffering and promote healing in those who seek their care. This workshop will focus on how doctors, nurses, and allied health care professionals serve in this way while maintaining equanimity and sense of meaning in their work and personal lives.

This 90-minute experiential-based workshop will be divided into three parts.

First, Mindful Clinical Practice will be described using narratives from different health care professionals in various settings. Mindful Congruence will be defined, along with Satir's four other communication stances.

Second, how the Four Noble Truths stemming from Buddhist philosophy inform clinical practice will be discussed with an emphasis on the Eightfold Path to end suffering.

Third, a model of Healing Relationships (Scott et al, 2008; 2009) will be used to help participants identify underlying processes contributing to the relational outcomes: hope, trust, and being known. An Appreciative Inquiry exercise will be used to enrich participants' understanding of their own experiences of being healers in clinical encounters.

(C) 2018 Patricia Lynn Dobkin. This article is distributed under the terms of the Creative Commons License $\underline{\mathrm{CC}}$ BY. International Journal of Whole Person Care

Vol 5, No 1 (2018) 
Mindful congruence, four noble truths and healing relationship Patricia Lynn Dobkin

If and how medicine may be a spiritual practice will be examined.

At the end of the workshop participants will be able to:

1. Define Mindful Congruence.

2. Understand how the Four Noble Truths from Buddhist philosophy inform clinical practice.

3. See how meditation practice contributes to clinicians' mindfulness and emotional regulation.

4. Discern the competencies and processes underlying healing. 